\title{
Jacques Cormier, L'atelier de Robert Challe (1659-1721)
}

\section{Jole Morgante}

\section{(2) OpenEdition}

\section{Journals}

\section{Édition électronique}

URL : http://journals.openedition.org/studifrancesi/5615

DOI : 10.4000/studifrancesi.5615

ISSN : 2427-5856

\section{Éditeur}

Rosenberg \& Sellier

\section{Édition imprimée}

Date de publication : 1 septembre 2011

Pagination : 405

ISSN : 0039-2944

\section{Référence électronique}

Jole Morgante, « Jacques Cormier, L'atelier de Robert Challe (1659-1721) », Studi Francesi [En ligne], 164

(LV | II) | 2011, mis en ligne le, consulté le 09 janvier 2021. URL : http://journals.openedition.org/ studifrancesi/5615; DOI : https://doi.org/10.4000/studifrancesi.5615

Ce document a été généré automatiquement le 9 janvier 2021.

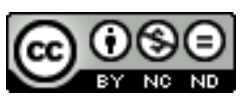

Studi Francesi è distribuita con Licenza Creative Commons Attribuzione - Non commerciale - Non opere derivate 4.0 Internazionale. 


\title{
Jacques Cormier, L'atelier de Robert Challe (1659-1721)
}

\author{
Jole Morgante
}

\section{RÉFÉRENCE}

JACQUES CORMIER, L'atelier de Robert Challe (1659-1721), préface de Geneviève ARTIGAS-

MENANT, Paris, PUPS, 2010, 651 pp.

1 Con questo volume composito Cormier sembra volere offrire una summa dell'autore di cui egli ha contribuito ad individuare la fisionomia, per darne una visione globale ed insieme dettagliata a diversi livelli.

2 Tale sguardo d'insieme, poggiato su una lunga esperienza professionale, è percettibile già nell'introduzione del volume (La résurrection d'une ceuvre, pp.15-23) dove si ricostruisce il lavoro critico che, sulla scia delle proposte di Frédéric Déloffre, ha permesso di realizzare una vera e propria scoperta letteraria grazie alla ricostruzione della figura di uomo e di scrittore di Challe, cui venivano attribuite sin dal xviII secolo, sia pure in modo vago, le Illustres Françaises e altre opere di vario argomento ma pubblicate tutte anonime, senza che tali attribuzioni portassero però ad una vera capacità di valutare la portata ed il ruolo dello scrittore (ivi compresa la difficoltà di identificarne correttamente il nome).

3 Il volume si compone quindi di un ampio saggio che percorre i diversi passaggi dell'attività di scrittura dell'autore (Pour une histoire de la création challienne, pp. 27-400), da una riedizione di articoli di Cormier (7) che permettono di documentare alcuni punti forti di questa produzione multiforme (Quelques aspects de la création challienne, pp. 403-531), di una sezione di Annexes che propone alcuni passaggi di opere, di Challe e di altri autori, la cui lettura offre un utile riscontro alle riflessioni critiche proposte da Cormier nel saggio che forma la prima parte del volume. Un'ampia ed articolata bibliografia ragionata (pp. 567-651) completa infine il volume e, insieme, la sua 
indubbia capacità di proporsi come indispensabile punto di riferimento per le ulteriori ricerche critiche, e non solo degli specialisti di Challe.

Uno dei risultati interessanti del lavoro critico proposto da Cormier è infatti la messa in luce del ruolo di vera e propria cerniera svolto dallo scrittore; favorito in parte dalla sua posizione a cavallo tra due secoli, esso è soprattutto dovuto alle caratteristiche della sua scrittura - dalle scelte stilistiche a quelle tematiche - ed è nutrito dalla sua grande attenzione ad un diversificato patrimonio culturale e alla più bruciante attualità. Così, se si tiene conto del ruolo seminale assunto dai riferimenti agli scritti di Camus in tutta l'opera e dell'importanza data agli eventi storico-politici della prima fase del regno di Louis XIV grazie all'ambientazione delle Illustres Françaises, si può dire che Challe costituisce a più di un titolo una vivace ed intensa sintesi del Seicento, mentre la sua capacità di dare voce ad istanze intellettuali ulteriormente riprese dagli autori del secolo dei Lumi conferma il valore di denuncia e di critica della sua riflessione, proprio a partire dai limiti e dalle discrepanze del Grand siècle che egli vide anche nel suo tramonto.

5 L'analisi puntuale delle opere proposta nel saggio di Cormier, dalla Continuation del Don Quichotte ai diversi racconti di viaggio e alle memorie, mostra come in Challe, alla capacità di aderire alle esigenze enunciative di generi distanti tra loro, si accompagni una notevole continuità che è insieme stilistica e tematica e che è in gran parte da ricondurre alla personalità dell'autore, capace di imprimere una forte tensione espressiva alla sua scrittura e di fare di essa uno strumento di presa di posizione ideologica anche molto rischiosa. Ciò spiega la pratica di un anonimato che ha reso a lungo poco agevole l'individuazione della coerenza che profondamente connette opere altrimenti disparate; Cormier ha quindi cura di provare che il raggiungimento di un acme creativo con le Illustres Françaises (del 1713) si apre poi ad un ulteriore sviluppo della scrittura in cui, alla continuità di procedimenti che contribuiscono al valore di quello che è ormai riconosciuto come un capolavoro narrativo, si accompagnano soluzioni che danno la misura di una crescente consapevolezza dei suoi mezzi da parte dello scrittore. Tale consapevolezza è favorita dal successo ottenuto con il romanzo, a dispetto delle difficoltà cui va incontro l'autore anche a causa della sua libertà di pensiero e nonostante la pratica dell'anonimato.

6 Se i diversi capitoli del saggio critico individuano come altrettante tappe le diverse opere, esso è attraversato da una duplice tensione dimostrativa retta l'una dalla centralità delle Illustres Françaises e l'altra dall'individuazione dell'eco che lo scrittore trova negli autori cardine del xviII secolo. Ora, se in certi casi gli effetti di ripresa in Voltaire, Diderot o Rousseau non sorprendono in ragione della pregnanza delle questioni che vi sono connesse, dall'altra tale ripresa fa intravedere la complessa problematicità delle contiguità e delle influenze spesso sollevati dallo studio letterario. Ma è vero comunque che lo sforzo argomentativo sotteso al saggio conserva in parte l'impronta pioneristica degli studi su Challe cui Cormier ha partecipato in prima persona, anche se, alla luce della ricezione critica attuale, lo statuto dell'autore e del suo capolavoro appare ormai nettamente definito. Ed è proprio da questo punto di vista che il saggio s'impone all'attenzione quando l'analisi spesso molto dettagliata delle altre opere permette di cogliere - anche grazie alla citazione prolungata di testi poco noti - i nessi molteplici che fondano la continuità ed il progredire della scrittura di Challe. 


\section{AUTEURS}

\section{JOLE MORGANTE}

it 